\title{
Sporcularla Sedanter Bireylerin Olumlu Düşünme Becerileri Üzerine Bir Karşılaştırma*
}

\author{
Okan Burçak ÇELİK ${ }^{\dagger 1}$, Oğuz Kaan ESENTÜRK ${ }^{2}$, Ekrem Levent İLHAN ${ }^{3}$ \\ ${ }^{1}$ Gazi Üniversitesi, Spor Bilimleri Fakültesi. https://orcid.org/0000-0001-9734-6822 \\ ${ }^{2}$ Erzincan Üniversitesi, Eğitim Fakültesi. https://orcid.org/0000-0002-0566-838X \\ ${ }^{3}$ Gazi Üniversitesi, Spor Bilimleri Fakültesi. https://orcid.org/0000-0002-1117-2700
}

Orijinal Makale

Gönderi Tarihi: 26.04.2020
Kabul Tarihi: 07.06.2020
DOI: $10.30769 /$ usbd.726995

Online Yayın Tarihi: 30.06.2020

\section{Öz}

$\mathrm{Bu}$ araştırmanın amacı, sporcularla sedanter bireylerin olumlu düşünme becerilerini karşılaştırmaktır. Araştırmanın çalışma grubunu Ankara ilinde ikamet eden 425 kişi oluşturmuştur. Katılımcıların 208'i sporcu, 217'si ise sedanterdir. Araştırmada veri toplama aracı olarak Kişisel Bilgiler Formu'nun yanı sıra Olumlu Düşünme Becerileri Ölçeği kullanılmıştır. Verilerin analizinde, ikili karşılaştırmalarda bağımsız örneklem t testi, değişkenler arasındaki ilişkilerde ise Pearson Momentler Çarpım Korelasyon Katsayısı (r) kullanılmıştır ve .05 anlamlılık düzeyi dikkate alınmıştır. Araştırma sonucunda, erkeklerin kadınlara, sporcuların da sedanter bireylere göre olumlu düşünme becerilerinin daha iyi düzeyde olduğu belirlenmiştir. Ayrıca katılımcıların yaşlarıyla olumlu düşünme becerileri arasında negatif yönde anlamlı bir ilişkinin olduğu sonucuna ulaşılmıştır. Sonuç olarak, düzenli olarak spor yapılmasının olumlu düşünme becerisini geliştireceği düşünülmektedir.

Anahtar kelimeler: Elit Sporcu, sedanter birey, olumlu düşünme.

\section{A Comparison on Positive Thinking Skills of Athletes and Sedentary Individuals}

\begin{abstract}
The purpose of this research is to compare the positive thinking skills of athletes and sedentary individuals. The study group of the research consisted of 425 people residing in Ankara. 208 of the participants are athletes and 217 are sedentary. In the research, Positive Thinking Skills Scale was used in addition to the Personal Information Form as a data collection tool. In the analysis of the data, independent sample t test was used in bivariate comparisons, and Pearson Product-moment Correlation Coefficient (r) was used in the relationships between variables and .05 significance level was taken into consideration. As a result of the research, it was determined that male's positive thinking skills were better than females, and also the positive thinking skills of athletes were better than sedentary individuals. In addition, it was concluded that there was a negatively significant relationship between participants' ages and their positive thinking skills. As a result, it is thought that regular sports and exercise will improve positive thinking skills.
\end{abstract}

Keywords: Elite athletes, sedentary individuals, positive thinking.

\footnotetext{
* Bu çalışma, 31 Ekim-3 Kasım 2018 tarihlerinde Anyalya'da düzenlenen 16. Uluslararası Spor Bilimleri Kongresinde sunulan bildirinin genişletilmiş versiyonudur.

${ }^{\dagger}$ Sorumlu yazar: Okan Burçak ÇELİK, e-posta: okanburcakcelik@ hotmail.com
} 


\section{GíRiş}

Günümüz dünyasında insanlar; küresel ısınma, doğal afetler, ekonomik durgunluk, benzeri görülmemiş evsizlik, terör ve savaşların bunaltıcı şekilde sürmesi şeklinde son derece önemli sorunlar ile karşı karşıyadır (Doğan, 2014). Son y1llarda giderek artan depresyon, kayg1, duygu durum bozuklukları gibi ruhsal sağlığı doğrudan etkileyen durumlara ek olarak küresel salgınlar gibi çeşitli hastalıklarla da mücadele etmek zorunda kalan modern insanın durumu, psikolog ve psikiyatristleri yeni arayışlara yöneltmektedir. Seligman (2002), psikiyatride yaygın bir anlayış olan "hastalık merkezli" psikoterapinin yerine koruyucu sağlık uygulamalarına benzer şekilde ruh sağlığını korumak ve hastalıkları önlemek için erdemleri, bireylere kazandırmayı amaçlayan, bireyin karakter güçlerini geliştirmeyi hedefleyen "yetkinlik bina etme merkezli" yaklaşımın, bilim çevrelerince oldukça ilgi gördüğünü belirtmektedir. Bireylerin çeşitli sorumluluklarına karşı endişe ile yaklaşmak yerine farklı bakış açıları oluşturarak, olaylara daha objektif ve cesur yaklaşabilmek adına olumlu düşünme becerilerini geliştirmeleri ve bu doğrultuda çözümler üretmeleri beklenmektedir.

Olumlu düşünme, bireylerin geleceğe dair umutlu imajlara sahip olmalarına yardımcı olan (Bekhet \& Zauszniewski, 2013), iyimser fikirler geliştiren, sorunlara uygun çözümler bulan, olumlu kararlar veren ve hayata genel bir bakış açısı getiren bilişsel bir süreçtir. Pozitif düşünme gerçekçi değerlendirme ihtiyacını göz ardı etmez. Aksine, sorunların, olayların ve olumsuzlukların hem olumsuz hem de olumlu yönlerini kabul eder ve ardından olumlu bir odaklanmaya ve yoruma doğru hareketi destekler (Tod, Warnock \& Allmark, 2011). Olumlu düşünme, bireyin, kendine yardımı (Bilge, 2012) olarak görülmekte ve hastalıklar dahil olumsuzluklarla başa çıkmak için yararlı bir strateji olarak önerilmektedir (Tod, Warnock \& Allmark, 2011). Literatürde iyimserliğin ve olumlu düşünmenin stres, kaygı ve depresyonun etkilerini azalttığına dair yapılmış araştırmalar bulunmaktadır (Ahangarzadeh vd., 2017; Gustafsson \& Skoog, 2012; Nikmanesh \& Zandvakili, 2015; Rajandram vd., 2011; Singh \& Jha, 2013; Sumi, 1997; Wong, 2012; Zandvakili vd., 2014; Zenger vd., 2010).

Hiç şüphe yok ki stres, kaygı, hastalıklar ve diğer pek çok olumsuzluk insan hayatının bir parçasıdır fakat aşılmaz, yenilmez ya da başa çıkılamaz değildir. Olumlu düşünmenin yanı sıra bu gibi problemlerle başa çıkmanın önemli stratejilerinden bir diğerinin de spor ve egzersiz olduğunu söylemek yanlış olmayacaktır. Spor ve egzersiz bu yönüyle olumlu düşünmenin önemli bir paydaşı olarak nitelendirilebilir. Nitekim, bazı bilimsel araştırmalar spor ve egzersizin depresyon ve kaygı belirtilerini azalttığını ve mental iyi oluşa katk1 sağladığını göstermiştir (Canan \& Ataoğlu, 2010; Eime vd., 2013; Malm vd., 2019; McMahon vd., 2016; McPhie \& Rawana, 2015). Yukarıda bahsedilen araştırmaların sonuçlarından hareketle, düzenli olarak spor ve egzersiz yapan insanların hayatın zorluklarıyla mücadele etme konusunda bir adım önde olduğu söylenebilir. Spor ve egzersizin mutluluğu artırdığı (Gatab \& Pirhayti, 2012) düşünüldüğünde sporcuların pozitif bir ruh haline sahip olmaları ve olumlu düşünme becerilerinden etkili bir şekilde faydalanabilmeleri daha olasıdır.

$\mathrm{Bu}$ araştırma, sporcularla sedanter bireylerin olumlu düşünme becerilerinin karşılaştırmalı olarak incelenmesi amacıyla yapılmıştır. Olumlu düşünme kavramı pek çok farklı alanda 
araştırmalara konu olmasina rağmen (Ayres, 1988; Caprara, Steca, Gerbino, Paciello \& Vecchio, 2006; De Raeve, 1997; Naseem \& Khalid, 2010), sporcularla sedanter bireyleri karşlaştıran bir araştırmaya rastlanmaması mevcut araştırmanın bu konuda gelecekte yapılacak çalsşmalar için bir referans teşkil edeceği düşünülmektedir.

\section{YÖNTEM}

\section{Araştırma Modeli}

$\mathrm{Bu}$ araştırmada tarama modeli kullanılmıştır. Tarama (survey) modeli bir grubun belirli özelliklerini belirlemek için verilerin toplanmasını amaçlayan çalışmalardır (Büyüköztürk vd., 2019). Karasar'a (2008) göre tarama modelleri geçmişte ya da halen var olan bir durumu var olduğu şekliyle betimlemeyi amaçlayan araştırma yaklaşımlarıdır.

\section{Çalışma Grubu}

Araştırmanın çalş̧̧a grubunu Ankara ilinde ikamet eden 425 kişi oluşturmuştur. Katılımcıların 208'i sporcu, 217'si ise sedanterdir. Çalışma grubunun frekans ve dağıllımları tablo 1'de verilmiştir.

Tablo 1. Katılımcıların spor yapma durumlarına göre dağılımları

\begin{tabular}{lcc}
\hline Katılımcilar & $\mathbf{N}$ & \% \\
\hline Sporcular & 208 & 48,9 \\
Sedanter & 217 & 51,1 \\
Toplam & 425 & 100,0 \\
\hline
\end{tabular}

\section{Veri Toplama Aracı}

Araştırmada veri toplama aracı olarak, Kişisel Bilgiler Formu'nun yanı sıra Bekhet \& Zauszniewski, (2013) tarafindan geliştirilen ve Akın, Uysal \& Akın (2015) tarafindan Türkçe’ye uyarlanan Olumlu Düşünme Becerileri Ölçeği (ODBÖ) kullanılmıştır.

\section{Kişisel Bilgiler Formu}

Kişisel bilgiler formunda cinsiyet ve yaş bilgilerinin yanı sıra, elit sporcunun ve sedanter bireyin tanımı yapılarak katılımcılardan hangi kategoride yer aldıklarını belirtmeleri istenmiştir.

\section{Olumlu Düşünme Becerileri Ölçeği}

Olumlu Düşünme Becerileri Ölçeği 8 maddeden oluşan bir ölçme aracıdır. Ölçek 4'lü bir derecelendirmeye sahiptir ("0" Hiçbir zaman, "1" Nadiren, "2" Genellikle, "3" Her zaman). Ölçekte ters kodlanan madde bulunmamaktadır. Yüksek puanlar olumlu düşünme becerilerinin daha sıklıkla kullanıldığını göstermektedir. Ölçekten alınabilecek en yüksek puan 24 , en düşük puan 0 'dır. Ölçeğin uyum geçerliği için yapılan çalışmada pozitif düşünme becerileri ile depresyon $(\mathrm{r}=-.45$, ) arasında negatif; genel iyi olma $(\mathrm{r}=.40)$ ve beceriklilik $(\mathrm{r}=$ .63) arasında pozitif ilişkiler bulunmuştur. Ölçeğin Cronbach alfa iç tutarlılık güvenirlik katsayısı .90 olarak bulunmuştur (Akın vd., 2015). Mevcut araştıma için Cronbach alfa iç tutarlılık katsayıs1 .86 olarak bulunmuştur. 


\section{Verilerin Analizi}

Öncelikle verilerin basıklık ve çarpıklık değerlerine bakılmış ve bu değerlerin $+1,5$ ile $-1,5$ arasında olduğu belirlenmiştir. Bu değerler verilerin normal dağıldığını anlamına gelmektedir (Tabachnick \& Fidell, 2013). Bu sonuçlara göre ikili karşılaştırmalarda bağımsız örneklem t testinden, değiş̧kenler arasındaki ilişkilerde ise Pearson Momentler Çarpım Korelasyon Katsayısı (r) kullanılmıştır. Verilerin analizinde .05 anlamlılık düzeyi esas alınmıştır.

\section{BULGULAR}

$\mathrm{Bu}$ bölümde verilerin analiz edilmesi sonucunda elde edilen bulgular tablolar halinde verilerek yorumlanmıştır.

Tablo 2. Cinsiyete göre olumlu düşünme becerilerini gösteren t-testi sonuçları

\begin{tabular}{lcccccc}
\hline Cinsiyet & N & X & SS & sd & t & p \\
\hline Erkek & 181 & 2.20 & .47 & \multirow{2}{*}{423} & 2.390 & \multirow{2017*}{*}{} \\
Kadın & 244 & 2.09 & .48 & & & \\
\hline
\end{tabular}

$* \mathrm{p}<.05$

Tablo 2 incelendiğinde, katılımcıların cinsiyetlerine olumlu düşünme becerileri arasında istatistiksel olarak anlamlı bir farklılığın bulunduğu görülmektedir. Bu farklılığın erkek katılımcıların lehine olduğu anlaşılmaktadır. Erkek katılımcıların olumlu düşünme berileri ortalama puanı $\mathrm{X}=2.20$ ve kadın katılımcıların olumlu düşünme berileri ortalama puanı $X=2.09$ 'dur. Bu sonuçlara göre erkeklerin kadınlara göre olumlu düşünme becerilerinin daha iyi olduğu söylenebilir.

Tablo 3. Yaş ve olumlu düşünme arasındaki ilişkiyi gösteren korelasyon analizi sonuçları

\begin{tabular}{lc} 
Değişkenler & Olumlu Düşünme \\
\hline Yaş & $-.080^{*}$ \\
\hline$* \mathrm{p}<.05$ &
\end{tabular}

Tablo 3 incelendiğinde, katılımcıların yaşlarıyla olumlu düşünme becerileri arasında negatif yönde anlamlı bir ilişkinin olduğu görülmektedir. Bu sonuçlara göre yaş arttıkça olumlu düşünmenin azaldığı söylenebilir.

Tablo 4. Sporcular ve sedanterlerin olumlu düşünme puanlarını karşılaştıran $t$ testi sonuçları

\begin{tabular}{lcccccc}
\hline Değişkenler & N & X & SS & sd & t & p \\
\hline Sporcular & 208 & 2.23 & .41 & \multirow{2}{*}{423} & \multirow{2}{*}{4.129} & \multirow{2}{*}{$.000^{*}$} \\
Sedanter & 217 & 2.04 & .53 & & & \\
\hline
\end{tabular}

$* \mathrm{p}<.05$

Tablo 4 incelendiğinde, katılımcıların spor yapma durumlarına göre olumlu düşünme becerilerinin istatistiksel olarak anlamlı farklılık gösterdiği görülmektedir. $\mathrm{Bu}$ farklılığın sporcu katılımcıların lehine olduğu anlaşılmaktadır. Sporcu katılımcıların olumlu düşünme 
becerileri ölçeğinden aldıkları puan $\mathrm{X}=2.23$ ve sedanter katılımcıların olumlu düşünme becerileri ölçeğinden aldıkları puan $\mathrm{X}=2.04$ 'tür. $\mathrm{Bu}$ sonuçlara göre sporcuların sedanter bireylere göre olumlu düşünme becerilerinin daha gelişmiş olduğu söylenebilir.

\section{TARTIŞMA VE SONUÇ}

$\mathrm{Bu}$ araştırma, sporcularla sedanter bireylerin olumlu düşünme becerilerini karşılaştırmak amacıyla yapılmış ve verilerin analizi sonucunda cinsiyet, yaş ve spor yapma değişkenlerine ilişkin elde edilen bulgular literatürdeki çalışmalar ışığında tartışılmıştır.

Araştırma sonucunda erkeklerin kadınlara göre olumlu düşünme becerilerinin daha iyi düzeyde olduğu sonucuna ulaşılmıştır. Literatür incelendiğinde, Karadağ'ın (2019) araştırmasında erkeklerin kadınlara göre olumlu düşünme becerilerinin daha iyi düzeyde olduğu sonucuna ulaştığı görülmektedir. Benzer şekilde Jacobsen vd., (2014) erkeklerin kadınlara göre pek çok konuda iyimser olmaya daha eğilimli olduklarını belirtmiştir. Aynı şekilde Puskar vd., (2010) erkeklerin kadınlardan daha iyimser olduğunu ifade etmiştir. Mevcut araştırmayı destekler nitelikte bir diğer araştırma da Cabras ve Mondo'nun (2018) araştırmasıdır. Diğer çalışmalardan farklı olarak Patton vd., (2004) iyimserlik konusunda erkekler ve kadınlar arasında anlamlı bir farklılığın olmadığını belirlemiştir. Benzer şekilde Tazegül (2018) araştırmasında, erkeklerin ve kadınların olumlu düşünme becerilerinin farklılaşmadığını vurgulamıştır. İnsanlık tarihine göz attığımızda neredeyse her toplum nezdinde erkek çocuklara, kız çocuklara kıyasla daha fazla önem verilmiş ve daha el üstünde tutulmuşlardır. Yakın tarihte yaşanan aydınlanmalar sonucunda kadınlara daha fazla önem verilmeye başlanmış ve kadınlar pek çok sektörde erkeklerle rekabet edebilmeye başlamışlardır. Bütün bu gelişmelerin yaşanmasına rağmen günümüzde hala kadınların hak ettikleri değeri gördüklerini söylemek zordur. İmkanlar anlamında tarihsel avantajını korumaya devam eden, fizyolojik üstünlüğe sahip olmasından dolayı başarı duygusunu daha iyi tanıyan ve el üstünde tutulan erkeklerin hayata daha pozitif bakması ve iyimser olması doğal karşılanabilir.

Araştırmada ayrıca katılımcıların yaşları ve olumlu düşünme becerileri arasında negatif yönlü ve anlamlı bir ilişkinin olduğu belirlenmiştir. Daha önce yapılan araştırmalar incelendiğinde, Tusaie ve Patterson'un (2006) araştırmasında iyimserlik ve yaş arasında negatif ilişki olduğu sonucuna ulaştığ fakat bu ilişkinin istatistiksel olarak anlamlı olmadığı görülmektedir. Chang (2002) genç yetişkinlere kıyasla yaşlıların anlamlı düzeyde daha iyimser olduğunu belirtmiştir. Zou vd., (2016) çocuklar ve adolesanlarda genel iyimserliğin yaşla pozitif ilişkiye sahip olduğunu bulmuştur. You vd., (2009) ise kültürlerarası araştırmalarında, Amerika'da yaşlıların iyimserliğe daha eğilimli olduğu sonucuna ulaşırken Çin'de tam tersi durumun olduğunu belirlemişlerdir. Jung vd., (2007) araştırmasında 30'lu yaşlarındaki insanların 40'lı ve 50'li yaşlarındaki insanlara göre olumlu düşünme puanlarının daha yüksek olduğunu ifade etmişlerdir. Bazı araştırmaların sonuçları mevcut araştırma sonuçlarıyla benzerlik gösterirken bazı araştırmaların sonuçları ise farklılık göstermiştir. Stres ve kayg1 faktörlerinin daha az, imkan ve olanakların daha fazla olduğu ortamlarda yaşamanın olumlu 
düşünmeyi ya da iyimserliği olumlu anlamda etkileyebileceği olasıllğı düşünüldüğünde, olumlu düşünme ve iyimserliğin kültürlerden ve yaşanılan ülkelerin özelliklerinden etkilenmesi ve değişkenlik göstermesi beklenebilir.

Araştırmada sporcuların sedanter bireylere göre olumlu düşünme becerilerinin daha iyi düzeyde olduğu bulunmuştur. Önceki araştırmalar incelendiğinde, Lipowski'nin (2012) sporcuların spor yapmayanlara göre daha fazla iyimserlik gösterdiği sonucuna ulaştı̆̆ görülmektedir. Benzer şekilde, Venne vd., (2006) üniversite son sinıf öğrencilerinde sporcuların sporcu olmayanlara göre daha iyimser olduklarını belirlemişlerdir. Diğer araştırmalardan farklı olarak Bostani ve Saiiari (2011) duygusal zekanın bileşenlerinden biri olarak, sporcularla sporcu olmayan öğrencilerin iyimserliklerini karşılaştırmış ve anlamlı bir farklılık olmadığını ifade etmiştir. Sporun hormonal ve psikolojik etkileri düşünüldüğünde, sporcuların daha pozitif ve iyimser olmaları olasıdır. Olumlu düşünme ve iyimser olma becerilerine sahip olmanın da sporun yarattığına benzer mental etkiler yarattığı dikkate alınırsa, sporun ve olumlu düşünme becerilerinin birbirini tamamlayan paydaşlar olduğunu söylemek yanlış olmayacaktır.

Sonuç olarak, bu araştırmada erkeklerin kadınlara göre, sporcuların da spor yapmayanlara göre olumlu düşünme becerilerinin daha iyi düzeyde olduğu sonucuna ulaşılmıştır. Ayrıca yaş ve olumlu düşünme becerileri arasında negatif yönde anlamlı bir iliş̧inin olduğu sonucuna ulaşılmıştır. Bu araştırmanın en önemli sınırlılığı örneklem grubunun tek bir ilden seçilmiş olmasıdır. Gelecek araştırmalarda daha büyük bir örneklem grubuyla daha kapsamlı bir araştrmanın yapılması önerilmektedir. Sporcularla sedanterleri karşılaştırma anlamında Türkçe literatürde öncü araştırmalardan olması ve daha sonra yapılacak araştırmalar açısından referans teşkil edecek olması araştırmanın olumlu yanlarından biri olabilir.

Yayın Etiği: $\mathrm{Bu}$ çalışmanın hazırlanma ve yazım sürecinde "Yükseköğretim Kurumları Bilimsel Araştırma ve Yayın Etiği Yönergesi" kapsamında bilimsel, etik ve alıntı kurallarına uyulmuş olup; toplanan veriler üzerinde herhangi bir tahrifat yapılmamış ve bu çalışma herhangi başka bir akademik yayın ortamına değerlendirme için gönderilmemiştir.

\section{KAYNAKLAR}

Ahangarzadeh Rezaei, S., Nematolahei, A. \& Oladrostam, N. (2017). The effect of positive thinking training on stress, anxiety and depression in coronary heart disease. The J Urmia Nurs Midwifery Fac, 15(5), 339-348.

Akın, A, Uysal, R \& Akın, Ü. (2015). Olumlu düşünme becerileri ölçeğinin Türkçe formunun geçerlik ve güvenirliği. Akademik Bakış Uluslararası Hakemli Sosyal Bilimler Dergisi, 51, 265-270.

Ayres, J. (1988). Coping with speech anxiety: The power of positive thinking. Communication Education, 37(4), 289-296. https://doi.org/10.1080/03634528809378730.

Bekhet, A. K. \& Zauszniewski, A. (2013). Measuring use of positive thinking skills: Psychometric testing of a new scale. Western Journal of Nursing Research, 35(8), 1074-1093. https://doi.org/10.1177\%2F0193945913482191. 
Çelik, O.B., Esentürk, O.K., ve İlhan, E.L. (2020). Düzenli egzersiz yapan bireylerin beslenme alışkanlıklarının incelenmesi. Ulusal Spor Bilimleri Dergisi, 4(1), 50-58.

Bilge, A. (2012). Yaşama dair olumlu düşünce. Ege Üniversitesi Hemşirelik Fakültesi Dergisi, 28(3), 129-135.

Bostani, M. \& Saiiari, A. (2011). Comparison emotional intelligence and mental health between athletic and non-athletic students. Procedia-Social and Behavioral Sciences, 30, 2259-2263. https://doi.org/10.1016/j.sbspro.2011.10.441.

Büyüköztürk, Ş., Kılıç-Çakmak, E., Akgün, Ö.E., Karadeniz, Ş. \& Demirel, F. (2019). Eğitimde bilimsel araştırma yöntemleri. Ankara: Pegem.

Cabras, C. \& Mondo, M. (2018). Coping strategies, optimism, and life satisfaction among first-year university students in Italy: Gender and age differences. Higher Education, 75(4), 643-654. https://doi.org/10.1007/s10734-017-0161-x.

Canan, F. \& Ataoğlu, A. (2010). The influence of sports on anxiety, depression, and perceived problem solving ability. Anatolian Journal of Psychiatry, 11(1), 38-43.

Caprara, G. V., Steca, P., Gerbino, M., Paciello, M. \& Vecchio, G. M. (2006). Looking for adolescents' wellbeing: Self-efficacy beliefs as determinants of positive thinking and happiness. Epidemiology and Psychiatric Sciences, 15(1), 30-43. https://doi.org/10.1017/S1121189X00002013.

Chang, E. C. (2002). Optimism-pessimism and stress appraisal: Testing a cognitive interactive model of psychological adjustment in adults. Cognitive Therapy and Research, 26(5), 675-690. https://doi.org/10.1023/A:1020313427884.

De Raeve, L. (1997). Positive thinking and moral oppression in cancer care. European Journal of Cancer Care, 6(4), 249-256. https://doi.org/10.1046/j.1365-2354.1997.00043.x.

Eime, R.M., Young, J.A., Harvey, J.T., Charity, M.J. \& Payne, W.R.. (2013). A systematic review of the psychological and social benefits of participation in sport for children and adolescents: Informing development of a conceptual model of health through sport. International Journal of Behavioral Nutrition and Physical Activity, 10(1), 1-21. https://doi.org/10.1186/1479-5868-10-98.

Gatab, T. A. \& Pirhayti, S. (2012). The effect of the selected exercise on male students' happiness and mental health. Procedia-Social and Behavioral Sciences, 46, 2702-2705. https://doi.org/10.1016/j.sbspro.2012.05.550.

Gustafsson, H. \& Skoog, T. (2012). The mediational role of perceived stress in the relation between optimism and burnout in competitive athletes. Anxiety, Stress \& Coping, 25(2), 183-199. https://doi.org/10.1080/10615806.2011.594045.

Hefferon, K. \& Boniwell, I. (2014). Pozitif Psikoloji: Kuram, araştırma ve uygulamalar (T. Doğan, Çeviri Editörü). Ankara: Nobel.

Jacobsen, B., Lee, J. B., Marquering, W. \& Zhang, C. Y. (2014). Gender differences in optimism and asset allocation. Journal of Economic Behavior \& Organization, 107, 630-651. https://doi.org/10.1016/j.jebo.2014.03.007.

Jung, J. Y., Oh, Y. H., Oh, K. S., Suh, D. W., Shin, Y. C. \& Kim, H. J. (2007). Positive-thinking and life satisfaction amongst Koreans. Yonsei Medical Journal, 48(3), 371-378. https://doi.org/10.3349/ymj.2007.48.3.371.

Karadağ, Ş. (2019). Üniversite öğrencilerinde olumlu düşünme becerisinin kişilerarası iletişim becerisi ile ilişkisi. Anemon Muş Alparslan Üniversitesi Sosyal Bilimler Dergisi, 7, 131-136.

Karasar, N. (2008). Bilimsel araştırma yöntemi. Ankara: Nobel.

Lipowski, M. (2012). Level of optimism and health behavior in athletes. Medical Science Monitor: International Medical Journal of Experimental and Clinical Research, 18(1), CR39-CR43. https://doi.org/10.12659/MSM.882200. 
Çelik, O.B., Esentürk, O.K., ve İlhan, E.L. (2020). Düzenli egzersiz yapan bireylerin beslenme alışkanlıklarının incelenmesi. Ulusal Spor Bilimleri Dergisi, 4(1), 50-58.

Malm, C., Jakobsson, J. \& Isaksson, A. (2019). Physical activity and sports-real health benefits: A review with insight into the public health of Sweden. Sports, 7(5), 1-28. https://doi.org/10.3390/sports7050127.

McMahon, E. M., Corcoran, P., O’Regan, G., Keeley, H., Cannon, M., Carli, V., ... \& Balazs, J. (2017). Physical activity in European adolescents and associations with anxiety, depression and wellbeing. European Child \& Adolescent Psychiatry, 26(1), 111-122. https://doi.org/10.1007/s00787-0160875-9.

McPhie, M. L. \& Rawana, J. S. (2015). The effect of physical activity on depression in adolescence and emerging adulthood: A growth curve analysis. Journal of Adolescence, 40C, 83-92. https://doi.org/10.1016/j.adolescence.2015.01.008.

Naseem, Z. \& Khalid, R. (2010). Positive Thinking in coping with stress and health outcomes: Literature review. Journal of Research \& Reflections in Education (JRRE), 4(1), 42-61.

Nikmanesh, Z. \& Zandvakili, M. (2015). The effect of positive thinking training on quality of life, depression, stress and anxiety in delinquent juveniles. Positive Psychology Research, 1(2), 53-63.

Patton, W., Bartrum, D. A. \& Creed, P. A. (2004). Gender differences for optimism, self-esteem, expectations and goals in predicting career planning and exploration in adolescents. International Journal for Educational and Vocational Guidance, 4(2-3), 193-209. https://doi.org/10.1007/s10775-005-1745-z.

Puskar, K. R., Marie Bernardo, L., Ren, D., Haley, T. M., Hetager Tark, K., Switala, J. \& Siemon, L. (2010). Self-esteem and optimism in rural youth: Gender differences. Contemporary Nurse, 34(2), 190-198. https://doi.org/10.5172/conu.2010.34.2.190.

Rajandram, R. K., Ho, S. M., Samman, N., Chan, N., McGrath, C. \& Zwahlen, R. A. (2011). Interaction of hope and optimism with anxiety and depression in a specific group of cancer survivors: a preliminary study. BMC Research Notes, 4, 1-7. https://doi.org/10.1186/1756-0500-4-519.

Seligman, M. E. P. (2002). Authentic Happiness. New York: Free Press.

Singh, I. \& Jha, A. (2013). Anxiety, optimism and academic achievement among students of private medical and engineering colleges: a comparative study. Journal of Educational and Developmental Psychology, 3(1), 222-233. https://doi.org/10.5539/jedp.v3n1p222.

Sumi, K. (1997). Optimism, social support, stress, and physical and psychological well-being in Japanese women. Psychological Reports, 81(1), 299-306. https://doi.org/10.2466\%2Fpr0.1997.81.1.299.

Tabachnick, B. G. \& Fidell, L. S. (2013). Using Multivariate Statistics. California: Pearson Education.

Tazegül, Ü. (2018). Elit düzeydeki tenisçilerin olumlu düşünme ve yaşama bağlılık düzeyleri arasındaki ilişkinin belirlenmesi. Akademik Bakış Uluslararası Hakemli Sosyal Bilimler Dergisi, 67, 16-25.

Tod, A., Warnock, C. \& Allmark, P. (2011). A critique of positive thinking for patients with cancer. Nursing Standard, 25(39), 43-47.

Tusaie, K. R. \& Patterson, K. (2006). Relationships among trait, situational, and comparative optimism: Clarifying concepts for a theoretically consistent and evidence-based intervention to maximize resilience. Archives of Psychiatric Nursing, 20(3), 144-150. https://doi.org/10.1016/j.apnu.2005.10.004.

Venne, S. A., Laguna, P., Walk, S. \& Ravizza, K. (2006). Optimism levels among collegiate athletes and non-athletes. International Journal of Sport and Exercise Psychology, 4(2), 182-195. https://doi.org/10.1080/1612197X.2006.9671792.

Wong, S. S. (2012). Negative thinking versus positive thinking in a Singaporean student sample: Relationships with psychological well-being and psychological maladjustment. Learning and Individual Differences, 22(1), 76-82. https://doi.org/10.1016/j.lindif.2011.11.013. 
You, J., Fung, H. H. \& Isaacowitz, D. M. (2009). Age differences in dispositional optimism: A cross-cultural study. European Journal of Ageing, 6(4), 247-252. https://doi.org/10.1007/s10433-009-0130-z.

Zandvakili, M., Jalilvand, M. \& Nikmanesh, Z. (2014). The effect of positive thinking training on reduction of depression, stress and anxiety of juvenile delinquents. International Journal of Medical Toxicology and Forensic Medicine, 4(2), 55-62.

Zenger, M., Brix, C., Borowski, J., Stolzenburg, J. U. \& Hinz, A. (2010). The impact of optimism on anxiety, depression and quality of life in urogenital cancer patients. Psycho-Oncology, 19(8), 879-886. https://doi.org/10.1002/pon.1635.

Zou, R., Zhang, D. J., Niu, G. F., Xie, X. C., Fan, C. Y., Tian, Y. \& Zhou, Z. K. (2016). Cross-sectional age differences in dispositional optimism in Chinese children and adolescents. Personality and Individual Differences, 102, 133-138. https://doi.org/10.1016/j.paid.2016.06.063.

Bu eser Creative Commons Atıf-GayriTicari 4.0 Uluslararası Lisansı ile lisanslanmıştır. 